\title{
Uma perspectiva sistêmico-discursiva para estudos em comunicação organizacional
}

\section{A systemic-discursive perspective for organizational communication studies}

\author{
Victor Márcio Laus Reis Gomes \\ Doutor em Comunicação Social. Professor e pesquisador do Programa de Pós-Graduação em Comunicação da UCB - \\ Universidade Católica de Brasília.
}

<victorlaus@gmail.com>

\section{RESUMO}

Este artigo aproxima a teoria dos sistemas de Niklas Luhmann e a abordagem discursiva de Eliseo Verón, com o objetivo de construir um quadro epistêmicometodológico para subsidiar estudos em comunicação organizacional. São discutidas as noções centrais da teoria sistêmica e os pressupostos da abordagem discursiva, de forma a possibilitar uma síntese da perspectiva sistêmico-discursiva, seus possíveis reflexos sobre a noção de comunicação organizacional, bem como a indicação de possíveis caminhos de investigação. Nessa perspectiva, a comunicação pode ser considerada a essência da organização. Através dela é construída e mantida a distinção fundamental que assegura sua condição sistêmica.

Palavras-chave: Teoria dos Sistemas. Abordagem discursiva. Comunicação Organizacional.

\begin{abstract}
This paper approaches Niklas Luhmann's systems theory and the discursive approach of Eliseo Verón, in order to build an epistemic and methodological framework to support organizational communication studies. The central concepts of systems theory and assumptions of the discursive approach are discussed in order to provide a synthesis of the systemicdiscursive perspective, as well as to indicate an alternative notion of organizational communication and its impact on research. In this perspective, communication can be considered the essence of the organization. Through which is built and maintained the fundamental distinction that ensures its systemic condition.
\end{abstract}

Keywords: Systems Theory. Discursive Approach. Organizational Communication.

\section{Introdução}

A teoria dos sistemas de Luhmann é reconhecida como uma opção paradigmática para trabalhos desenvolvidos nos campos dos estudos organizacionais e da comunicação organizacional (Soares, 2005; Curvello; Scroferneker, 2008; Curvello, 2009). No entanto, parece haver um espaço ainda pouco explorado para sua aplicação e articulação com teorias e técnicas de pesquisa em comunicação.

A comunicação pode ser considerada um elemento central para a teoria sistêmica de Luhmann (2005b; 2006; 2011). Conforme este autor, os sistemas sociais, incluindo as organizações, podem ser compreendidos como unidades operacionalmente fechadas e interativamente abertas, constituídas essencialmente por comunicação. Ela, por sua vez, é entendida 
como um processo de multiplicação de sentidos, que depende da interação entre indivíduos/sistemas. Essa multiplicação ocorre devido às diferenças, ou assimetrias, dos envolvidos no processo e, também, à própria natureza do sentido, que é multidimensional, construído e revelado em determinadas condições de produção e de reconhecimento.

A noção de comunicação como multiplicação de sentidosé fundamentada em Luhmann (2011), para quem a metáfora da transferência ou transmissão não é adequada à explicação do processo comunicacional. De acordo com Luhmann (2011, p. 294), "a comunicação é uma sucessão de efeitos multiplicadores". Assim, quando nos referimos à multiplicação de sentidos, não consideramos a noção matemática que pressupõe a manutenção de um mesmo objeto ou a soma finita de números iguais. A multiplicação é compreendida como uma sucessão de efeitos do processo comunicacional, que gera multiplicidade de sentidos.

Nesse contexto, de diferenças e de multidimensionalidade do sentido, há espaço para consenso e dissenso, conflito e cooperação, acertos e desvios, compreensão e incompreensão. A comunicação, como uma transmissão linear, em que o destinatário tem plena compreensão e aceitação dos conteúdos, das intenções e das atitudes dos emissores, parece improvável. Ela é, portanto, um espaço de multiplicação e de disputa de sentidos. As intenções, ou até mesmo a falta delas, se perdem em um universo de possibilidades de compreensões. Conforme Luhmann (2011), uma das formas de analisar se uma comunicação foi bem-sucedida é buscar o efeito dela em comunicações subsequentes.

O efeito de uma comunicação cria, segundo a teoria sistêmica, uma rede de comunicações. Verón (1980; 1997a), por sua vez, propõe a noção de rede social de semiose ou rede discursiva, em que determinados discursos, mediante seus efeitos de sentido, podem constituir as condições de produção de outros discursos. Assim, a ideia de "rede", em que os sentidos se multiplicam e os discursos produzem campos de efeitos, parece fornecer um caminho para a compreensão dos processos comunicacionais. É possível dizer que há uma circulação de sentidos na rede discursiva, entre produção e reconhecimento, que é revelada pela não linearidade e pode ser observada entre dois ou mais discursos relacionados.

Com a aproximação entre a teoria dos sistemas de Luhmann ea abordagem discursiva de Eliseo Verón, nosso objetivo é propor um quadro epistêmicometodológico para subsidiar estudos em comunicação organizacional. Neste artigo', discutimos, inicialmente, a teoria sistêmica, indicando seus principais

1 Trabalho desenvolvido com base na tese de doutorado do autor, que contou com apoio da CAPES. 
antecedentes e apresentando suas noções centrais: o fechamento operacional, o acoplamento estrutural e a autopoiese. Em seguida, apresentamos os pressupostos da abordagem discursiva. Por fim, sintetizamos as bases para a perspectiva sistêmico-discursiva e como elas podem ser articuladas, tanto para fundamentar abordagens comunicacionais, como para pensar a noção de comunicação organizacional.

\section{A teoria sistêmica de Luhmann}

Para o senso comum, a noção de sistema geralmente é associada a um conjunto de partes integradas, quefuncionam deforma a buscar constantemente um ajuste entre si e uma adaptação ao meio externo, processando entradas (insumos/inputs) e saídas (produtos/outputs). Um aspecto, no entanto, parece implícito nessa noção, embora pouco enfatizado: a diferença. No momento em que é assumida a existência de um meio externo, o que está fora não faz parte do sistema. É justamente sobre essa diferença que Luhmann (1997a, 1997b, 2011) constrói sua teoria. Para o autor, o objeto da teoria dos sistemas é a diferença entre sistema e ambiente. Uma diferença que se constitui e se reproduz através do próprio sistema.

A teoria assume um caráter universalista e passa a explicar tudo o que existe com uma diferenciação, que exige uma indicação, uma referência do que está dentro e do que está fora, do que é sistema e do que é ambiente. Somente com uma referência externa, heterorreferência, e uma referência a elementos internos, autorreferência, é possível distinguir os elementos de um sistema e as suas relações. Conforme Luhmann (1997a, p. 40), "a autorreferência só pode ocorrer num ambiente e somente com relação a um ambiente". O sistema pode, então, ser compreendido como a relação com o ambiente ou como a diferença entre ele próprio e o ambiente.

A diferenciação pode ser compreendida como uma forma reflexiva e recursiva de constituição dos sistemas. O sistema se reproduz através de operações internas, com ajuda de seus próprios elementos, agregando a cada operação uma nova operação do mesmo sistema. As operações se conectam a outras através de estruturas e são observadas pelo próprio sistema, de forma a garantir a reprodução, aparando as diferenças e mantendo o sistema. A observação pode ser considerada um tipo particular de operação, que trabalha com a distinção, ou seja, a capacidade de separar os dois lados de uma diferenciação (Marcondes Filho, 2005). O sistema, portanto, observa a si mesmo e ao ambiente, em um esforço contínuo de diferenciação. 
O sentido, construído a partir da observação e, consequentemente, dependente dela, é contingente e está subordinado à diferenciação do sistema. Com isso, para Luhmann (2011), não há diferença entre verdadeiro e não verdadeiro, assim como não há separação entre sujeito e objeto. O sentido pode ser remetido às operações de um sistema e considerado fruto de uma observação, que guarda um caráter de incompletude. Conforme Marcondes Filho (2004, p. 451), "as observações não estão jamais em condições de observar as distinções que elas mesmas fazem". Daí a necessidade de uma observação de segunda ordem, que procura desvendar aquilo que o observador não pode ver. Contudo, essa também não deixa de ser uma observação incompleta.

Uma pesquisa observa contingências e eventualidades, percebendo aspectos que fogem ao ponto cego do sistema observado. Temos um pesquisador (observador) que observa um objeto (que, por sua vez, também é um observador). Luhmann (2011) desloca a discussão sujeito/objeto para a diferença entre sistema e ambiente. Com isso, ele busca, de certa forma, isolar as questões sociais. Ao invés da dualidade sujeito/objeto, o que importa é observar o observar. Segundo Marcondes Filho (2004, p. 433), "esse é o sentido que Luhmann dá à comunicação: a capacidade de sistemas observarem e de se observar sua observação". Esses fundamentos marcam uma posição epistemológica central da teoria dos sistemas de Luhmann - o reconhecimento da incompletude da pesquisa. Podemos dizer que os objetos são contingentes, da mesma forma que as abordagens/leituras realizadas sobre eles.

As noções de fechamento operacional, acoplamento estrutural e autopoiese, desenvolvidas originalmente por Maturana e Varela (1995), são fortemente relacionadas e constituem a base para o desenvolvimento das propostas teóricas de Luhmann. Baseado em uma abstração das noções desses autores, Luhmann desenvolve sua própria concepção de fechamento operacional, de acoplamento estrutural e de autopoiese, aplicadas aos sistemas sociais.

Tendo como ponto de partida de sua teoria a disparidade entre sistema e meio, Luhmann (2011) defende que um sistema é uma forma de dois lados (re) produzida constantemente. Um desses lados, o lado interno, pode ser definido a partir de um operador. No caso dos sistemas sociais, esse operador é a comunicação. Através dela, a diferença entre o sistema social e o meioé produzida e reproduzida. Assim, podemos dizer que os sistemas sociais são formados por comunicação. Esses sistemas têm sua diferença construída por comunicações que se conectam a outras comunicações, desenvolvendo mais comunicação, 
constituindo uma estrutura circular, autopoiética², operacionalmente fechada, em acoplamento(s) com o ambiente. "Tudo o que existe e pode ser designado como social está constituído, do ponto de vista de uma construção teórica fundamentada na operação, por um mesmo impulso e um mesmo tipo de acontecimento: a comunicação" (Luhmann, 2011, p. 91).

O fechamento operacional dos sistemas sociais tem, para Luhmann (1997b), a mesma natureza que o fechamento do sistema cognitivo. Conforme o autor (1997b, p. 52), "nós conhecemos o mundo externo apenas porque o acesso a ele é bloqueado". O conhecimento é uma construção própria do sistema cognitivo, que não pode ser estruturada ou determinada pelo ambiente, apenas perturbada. Informações não são obtidas do entorno, são construtos internos gerados de acontecimentos observados no lado externo. $\mathrm{O}$ autor indica que no sistema não há representações do ambiente, somente construções próprias do sistema.

A comunicação é responsável pelo desenvolvimento de uma lógica própria de conexão com a comunicação seguinte, que inventa sua própria memória, diferenciando os sistemas sociais. O ambiente é observado através de uma atividade interna e mediante distinções próprias do sistema. De acordo com Luhmann (2011), o fechamento operacional é que possibilita o conhecimento nos sistemas sociais. Esse fechamento, no entanto, se refere exclusivamente à operação necessária para a autorreprodução dos sistemas. Ele não quer dizer que o sistema é completamente isolado do ambiente. Os sistemas sociais, na concepção de Luhmann (2011), guardam uma referência fundamental em relação ao meio e existem em função dela. Então, é possível dizer que o ambiente influencia ou perturba os sistemas sociais, e o fechamento operacional possibilita que esses sistemas sejam compatíveis com a desordem do ambiente.

Portanto, o fechamento não pressupõe falta de relação com o entorno. O sistema, segundo Luhmann (2011), se relaciona com o meio circundante através do acoplamento estrutural. Em abordagens anteriores, a relação com o ambiente era pensada mediante entradas e saídas. 0 acoplamento, por sua vez, considera o fechamento operacional e a relação com o ambiente a partir dos mecanismos internos de operação do sistema. Assim como a diferença

2 O adjetivo "autopoiética" é utilizado para designar uma estrutura (sistema) em que ocorre a autopoiese, ou seja, a capacidade de autorreproduzir-se exclusivamente através de seus próprios elementos e operações internas. No caso dos sistemas sociais, a comunicação e a rede de comunicações formada no interior do sistema constituem o elemento fundamental para a autorreprodução e são por ele responsáveis (Luhmann, 2011). 
entre ele e o ambiente é produzida pelo próprio sistema, as relações que este estabelece com o ambiente também são resultados dessas operações internas. Sob essa perspectiva, pode-se dizer que o entorno existe no momento em que os sistemas reconhecem e estabelecem a diferença.

Com isso, os sistemas estão associados ou acoplados a um determinado entorno. No processo de diferenciação são estabelecidos acoplamentos estruturais específicos, podendo fazer com que alguns acontecimentos do ambiente apareçam no sistema como informação e causem efeitos sobre ele, mas sem prejudicar a autonomia operativa do sistema. O acoplamento estrutural, como uma relação complexa, não pode ser explicada com uma lógica de causalidade linear (Luhmann, 2005a).

O sistema observa o mundo externo e converte acontecimentos em operações próprias, sendo as perturbações produzidas no interior do próprio sistema. Elas são oriundas de acontecimentos externos, mas resultados das operações internas. Os sistemas sociais, por exemplo, estão acoplados a sistemas neurofisiológicos e a sistemas psíquicos ou consciências. A irritação ou perturbação nos sistemas sociais são decorrentes da mediação das consciências sobre acontecimentos do ambiente externo. Luhmann (2005a) reconhece que só os sistemas psíquicos são capazes de perceber e de expressar essa irritação ou perturbação comunicativamente. $\mathrm{O}$ acontecimento externo pode irritar a comunicação quando é processado pelo filtro do sistema psíquico.

Nesse contexto, a linguagem é considerada por Luhmann (1997c) como o elemento responsável pelo acoplamento estrutural entre comunicação e consciência, ou seja, entre sociedade e indivíduo, mantendo esses sistemas separados. A linguagem pode perturbar a consciência através da comunicação ou perturbar a sociedade através da consciência. Como responsável pelo acoplamento estrutural entre sistemas sociais e indivíduos, a linguagem possibilita que o elemento externo ao sistema seja incorporado através da construção de sentido.

Essa construção, no entanto, é particular, única, própria de cada sistema social. A linguagem é portadora de sentido. Quando o sistema social se depara com a complexidade, ocorre um processo autorreferenciado de seleção de sentido através da linguagem. Tanto a autorreferência quanto a heterorreferência, ou a referência ao entorno, são construções dotadas de sentido. Os sentidos construídos nos sistemas podem, então, ser considerados como meios simbólicos para a redução da complexidade (Rodrigues; Neves, 2012). Dessa forma, parece que meios simbólicos ou sentidos consolidados em sistemas sociais tendem a se perpetuarem através da lógica autopoiética de reprodução desses sistemas. 
Fechado operacionalmente e acoplado ao ambiente, o sistema se autoobserva e se autorreproduz. Ele constrói internamente suas estruturas em um movimento circular, recursivo, que pode ser compreendido através da noção de autopoiese. Isso significa dizer que os sistemas são responsáveis pela produção de todas as unidades necessárias para a continuidade de sua operação. A circularidade da noção pode ser percebida nas palavras de Luhmann (2011, p. 120): “Na definição de Maturana, autopoiesis significa que um sistema só pode produzir operações na rede de suas próprias operações, sendo que a rede na qual essas operações se realizam é produzida por essas mesmas operações".

Os sistemas se autorreproduzem em um esforço de diferenciação, em que se diferenciam de tudo aquilo que não sejam eles mesmos. Essa diferenciação, no entanto, depende exclusivamente das operações internas, através das quais os sistemas se constituem autopoieticamente, e não do ambiente. A noção de autopoiese, portanto, preserva a unidade do sistema, sem assumir que todas as causas necessárias para o êxito do sistema precisam estar nele reunidas. $O$ fechamento operacional e a autopoiese se referem à constituição e à preservação da unidade do sistema, de forma que um observador possa compreender eventuais causas e efeitos dessa unidade sistêmica. $O$ acoplamento estrutural, por outro lado, indica que a dependência em relação ao ambiente é compatível com a autopoiese e com o fechamento operacional (Luhmann, 1997a).

Um aspecto central na noção de autopoiese de Luhmann (2011), que a distingue da noção de Maturana e Varela (1995), é a diferença entre estrutura e operação. Para a compreensão biológica da noção importam os estados químicos e as substâncias, que são estáveis, enquanto a noção sociológica é fundamentada na instantaneidade e na contingência da comunicação. No caso dos sistemas psíquicos e sociais, os elementos não são estáveis, e sim eventos momentâneos. Eles são definidos em sua integração ao sistema, ou seja, em sua relação com outros elementos. Fora ou independentemente do sistema, eles perdem o status de elementos.

Como não são constituídos de elementos estáveis, esses sistemas precisam estar continuamente produzindo novos elementos. Daí a centralidade da noção de rede de comunicação na perspectiva de Luhmann. A rede, portanto, pode ser pensada como a estrutura que é construída pelas operações. A autopoiese dos sistemas sociais está, então, na autorreprodução dessa rede. 


\section{A abordagem discursiva}

Inicialmente, faz-se necessário relembrar que a abordagem analítica proposta por Verón (1980, 1996, 1997a, 2004) foi originalmente pensada para explicar a comunicação midiática, que é compreendida como"uma configuração de meios de comunicação resultantes da articulação entre dispositivos tecnológicos e condições específicas de produção e de reconhecimento"(Verón, 1997b, p. 14). Essas condições compõem a estrutura do mercado discursivo das sociedades industriais. Nesse contexto, as mensagens são consideradas produtos ou sistemas de significação que circulam em um mercado discursivo. Os meios de comunicação social, por sua vez, são os dispositivos tecnológicos de produção e de reprodução de mensagens, que possuem acesso coletivo.

Para Verón (1997b), a comunicação midiática gera uma midiatização das sociedades industriais, que pode ser analisada mediante um esquema básico, o qual inclui os meios de comunicação social, as instituições, os atores individuais e as construções coletivas que se dão através das relações entre essas três instâncias. Este esquema confere uma centralidade para a comunicação na dinâmica das sociedades, principalmente quando destaca que os coletivos são constituídos a partir de operações comunicacionais. Nesse aspecto, parece possível uma aproximação entre a abordagem do autor e a noção de sociedade constituída por comunicação de Luhmann.

Quando se refere à sua concepção de abordagem discursiva, Verón (2004) chama a atenção para a utilização da expressão no plural: análise de discursos. Para o autor, o que circula e produz efeitos em uma sociedade são discursos. Podemos considerar os discursos como efeitos de sentidos em um contexto social. Esse enfoque social de sua abordagem é o elo em que nos apoiamos para estabelecer o vínculo com a teoria sistêmica de Luhmann. Conforme a seção anterior deste trabalho, compreendemos a linguagem como o meio que possibilita o acoplamento entre sistemas sociais e também entre esses e indivíduos (sistemas psíquicos ou consciências).

A relação entre sistemas sociais e psíquicos é de interpenetração, ou seja, há uma relação de dependência entre eles. Merece destaque esse aspecto, pois o estudo dos discursos pressupõe a presença de sujeitos, sejam eles indivíduos, instituições ou meios de comunicação. A perspectiva sistêmicodiscursiva que adotamos incorpora essa condição, compreendendo que há uma intencionalidade, assim como há referências pessoais, temporais e espaciais mencionadas por Maingueneau (2008), ou uma posição de enunciação ou lugar de fala, segundo nos diz Foucault (1999). Sob a perspectiva, no entanto, essa condição é considerada em um viés essencialmente social, indicando um olhar 
ou uma opção pela investigação dos aspectos sociais envolvidos na circulação de sentidos.

Tratamos, pois, de lances (enunciados) em jogos de linguagem (contextos de interações ou condições produtivas), para Lyotard (2002), que fazem circular ou multiplicar os sentidos. Esses lances são regidos por normas e têm relação com um interdiscurso, com um universo de outros discursos (Maingueneau, 2008), com um pré-construído (Pêcheux, 2009), com uma nuvem de linguagem (Lyotard, 2002), ou com uma rede discursiva (Verón, 1996). Essa relação com o interdiscurso parece revelar uma autorreferencialidade sistêmica dos jogos de linguagem e, consequentemente, dos discursos. O enunciado, por sua vez, é compreendido como uma unidade da comunicação verbal construída entre os envolvidos no processo de comunicação, socialmente contextualizados (Bakhtin, 1992). Ele pode ser considerado uma unidade elementar do discurso (Henry, 1993).

De acordo com Verón (2004), um dispositivo de enunciação é composto pelo enunciado (conteúdo) e pela enunciação, que configura a relação do enunciador com o dizer, como a imagem de quem fala, a imagem daquele a quem o discurso é endereçado e a relação entre enunciador e destinatário proposta no discurso. A esta noção de dispositivo de enunciação parece possível associar o jogo de linguagem. O lance de linguagem (enunciado) é dado no contexto de um jogo onde são assumidas posições, expectativas e disputas. É através dos dispositivos de enunciação que são estabelecidos contratos de leitura (Verón, 2004). A posição didática, a transparência, a partilha de valores, o grau e o tipo de saber atribuído ao leitor, são elementos que revelam esses contratos.

O ponto de partida para a análise é o sentido produzido, materializado em discursos. Toda a produção de sentido apresenta uma manifestação material. O discurso, independente do suporte material, é uma configuração espaço-temporal de sentido, ou seja, ele pode ser considerado uma construção do sentido no espaço-tempo. Segundo Verón (1980), para conduzir a análise, é preciso acessar a rede discursiva, ou rede semiótica, a partir de fragmentos do processo semiótico. A fragmentação transforma pequenos pedaços do tecido da semiose em produtos para serem analisados. Conforme o autor, a semiose social é a dimensão significante dos fenômenos sociais e envolve o estudo desses fenômenos enquanto processos de produção de sentido.

Nesse contexto, seria possível assumir toda produção de sentido como social e todo funcionamento social como um processo de produção de sentido, que possui uma dimensão significante. Considerando o sentido intimamente relacionado com os comportamentos sociais, Verón (1980) defende que a 
produção de sentido consiste no verdadeiro fundamento das representações sociais, assim como Luhmann (2011) defende que o sentido determina as fronteiras operativas dos sistemas sociais. A realidade social seria, então, construída na semiose:

A análise dos discursos sociais abre caminho, desta maneira, para o estudo da construção social do real, [...]. Uma teoria dos discursos sociais pode ter como meta a análise da produção do real-social, sem complicar-se com um modelo subjetivista do ator (Verón, 1980, p. 126).

A teoria do discurso de Verón é construída sobre uma hipótese de defasagem entre as noções de "produção" e de "reconhecimento", guardando semelhanças com as noções de emissão e de recepção da teoria da comunicação. A problemática da comunicação, para o autor, está justamente nessa defasagem. Há uma não linearidade entre produção e reconhecimento, implicando que um discurso nunca produz um efeito único, mas um campo de efeitos. A não linearidade expressa uma circulação de sentidos em um sistema em desequilíbrio. A defasagem entre produção e reconhecimento se manifesta quando, do lado da produção, é possível descrever ou reconstruir as regras que compõem a classe de textos analisada. No entanto, do lado do reconhecimento, há uma variedade de leituras possíveis.

Um mesmo discurso pode ter múltiplos efeitos, graças à não linearidade da relação entre produção e recepção. Os discursos circulam entre condições de produção e condições de reconhecimento. A análise não pode considerar o objeto em si mesmo. Ela precisa considerar a relação do objeto com aspectos determinados das condições, buscando as pistas ou marcas dessas nos textos analisados. Os "objetos" que interessam à análise de discursos sociais são "sistemas de relações que todo produto significante mantém com suas condições de produção, de um lado, e com seus efeitos, de outro." (Verón, 1996, p. 128).

O sentido se constitui, portanto, de uma relação infinita entre produção e reconhecimento, que forma uma rede discursiva, também referida por Verón (1996) como uma rede textual histórica. Compreender essa rede, e as relações estabelecidas entre produção e reconhecimento que se configuram em seu âmbito, parece ser um aspecto central da proposta de Verón. Em nossa perspectiva sistêmico-discursiva, é afirmar que uma comunicação pode ser compreendidaa partir de seus efeitos sobre comunicações futuras. Consideramos que a abordagem discursiva de Verón traz um aporte metodológico para a 
perspectiva sistêmico-discursiva, valorizando o aspecto social da produção de sentido e revelando a sua autorreferencialidade.

\section{A perspectiva sistêmico-discursiva, as organizações e a comunicação}

A origem da perspectiva sistêmico-discursiva está na compreensão dos sistemas sociais como unidades operacionalmente fechadas e interativamente abertas, que têm a comunicação como sua operação essencial. É através da comunicação que a diferença sistema social/ambiente é (re)produzida continuamente, garantindo a manutenção do sistema e procurando reduzir a complexidade do ambiente. Essa diferenciação parece seguir um movimento reflexivo e recursivo em que o sentido é construído em redes de comunicações, que operam de forma circular, autopoiética e operacionalmente fechada. 0 sistema observa o entorno e constrói sentido tendo por referência esse tecido autorreferenciado de comunicações.

Os sentidos circulam nessas redes, e constituem o horizonte operativo dos sistemas sociais, os quais, apesar de operacionalmente fechados, não estão isolados. A linguagem possibilita acoplamentos estruturais com indivíduos e outros sistemas, permitindo que elementos externos aos sistemas sejam incorporados, mantendo, no entanto, a autorreferencialidade na construção dos sentidos. Ou seja, o sistema tem contato com o mundo externo, mas constrói o sentido segundo suas referências internas. Isso garante a identidade, mantendo a diferenciação sistema/ambiente.

Nesse contexto, os discursos são efeitos de sentidos construídos nos sistemas sociais. Podem ser compreendidos também como lances de linguagem ou enunciados que, em jogos de linguagem, materializam os sentidos que circulam nos sistemas. Esses lances parecem estar submetidos a regras e acordos, explícitos ou tácitos, que são intrínsecos à condição de fechamento dos sistemas sociais. Além disso, os lances configuram um contexto social e, com isso, assumem posições, expectativas e disputas.

A perspectiva sistêmico-discursiva contribui para direcionar a atenção da investigação à dimensão social do discurso, não ignorando o sujeito, mas deslocando a atenção para a diferença sistema/ambiente e para a dinâmica social da construção de sentidos, o que parece abrir novas possibilidades de compreensão em torno da comunicação organizacional.

Conforme Luhmann (2005b), na sociedade, as organizações se distinguem e se reproduzem a partir de um tipo específico de comunicação: a decisão. Cada decisão produz e reproduz a distinção organização/ambiente. Com isso, 
as organizações podem ser compreendidas como sistemas autorreferenciais de (re)produção de decisões.

Da mesma forma que a comunicação não pode prescindir dos indivíduos, a organização, para existir, também depende dos indivíduos. No entanto, de acordo com a teoria sistêmica de Luhmann (2005b, 2011), os indivíduos também são sistemas (sistemas psíquicos ou consciências) e fazem parte do ambiente da organização. Eles se relacionam com as organizações através de acoplamentos estruturais. Compreendemos, assim, que não são os indivíduos que conferem forma à organização, mas a comunicação. É, portanto, nesse sentido que podemos dizer que a organização é formada por comunicação.

Quando consideramos o acoplamento entre indivíduos e organizações, podemos pensar em uma relação mutuamente constitutiva, mediada pela linguagem, que é condição para a existência da comunicação e, consequentemente, do sistema organizacional. Nesse contexto, a noção sistêmica de organização está fundamentada na comunicação, que garante as condições estruturais para a existência da organização.

De forma autopoiética, as organizações definem os requisitos para a participaçãoe selecionam quem está apto a participar, assim como decidem sobre seus propósitos e definem tarefas, posições e papéis, que acabam por constituir as premissas para outras decisões. As decisões, para Luhmann, constituem, antes de uma operação mental, uma forma específica de comunicação. Nesse sentido, as decisões não são tomadas e depois comunicadas. As decisões são comunicação. Como as decisões são constituídas por duas distinções entrelaçadas, uma decisão envolve a comunicação, explícita ou implícita, de uma alternativa selecionada e de alternativas rejeitadas.

Assim, a comunicação de uma decisão é paradoxal. Ela informa sobre a decisão, mas também sobre as alternativas, que, reitere-se, são e não são alternativas; caso contrário não haveria decisão. Por ser paradoxal, a comunicação da decisão é frágil e demanda uma desconstrução através de comunicações posteriores. Cada decisão funciona como uma premissa decisória para decisões futuras. A absorção da incerteza ocorre, portanto, quando uma decisão é utilizada como premissa para decisões futuras. As premissas podem restringir ou criar novas situações de decisão, limitar ou facilitar novas decisões. Para Luhmann (2005b), é a "rede de decisões" que decide.

A noção de decisão de Luhmann (2005b) é abrangente e não se restringe a comportamentos regidos por uma ideia de racionalidade absoluta. Compreender a decisão como uma forma de comunicação pressupõe considerar a racionalidade múltipla envolvida nos comportamentos decisórios. Assim, a 
decisão deixa de ser um processo sequencial, linear, consciente, deliberado e planejado, em que um conjunto de alternativas é avaliado, e a melhor escolha é feita, passando a ser compreendida como a expressão de um conjunto amplo de fatores inter-relacionados que, além da razão, envolvem afeto, intuição e relações sociais. Dessa forma, o processo decisório pode ser compreendido como não linear e transitório. Essas características também são ressaltadas por abordagens que procuram integrar os aspectos cognitivos e afetivos do processo decisório, como as de Simon (1970) e de Leitão (1997).

$\mathrm{Na}$ perspectiva sistêmico-discursiva, consideramos a decisão em sua dimensão social. Em uma rede dinâmica e complexa, as decisões parecem ser geradas a partir de efeitos de sentidos e representam a inter-relação de fatores de ordem cognitiva, emotiva e social. Nessa perspectiva, a decisão ainda revela uma interface fundamental da relação entre organização e comunicação. Como efeitos de sentidos, as decisões podem ser compreendidas como discursos. A comunicação organizacional, portanto, é construída em/por decisões. 0 que nos leva a assumir que um texto, produzido e reconhecido no âmbito da comunicação organizacional, pode ser considerado a materialização de uma ou mais decisões. Para Verón (1997b, p.12), um texto é "um objeto ou produto pertencente a um sistema primário se significação", enquanto um discurso é uma forma de aproximação, de manipulação ou de abordagem ao texto. No contexto organizacional, sob a ótica sistêmico-discursiva, as decisões são fruto de processos de construção de sentido e estão materializadas nos textos que circulam em processos de comunicação organizacional.

Diferente de noção linear de comunicação, que considera a transmissão assimétrica de significados ou de informações de um emissor a um receptor, a comunicação é compreendida por Luhmann (2011) como a síntese de três componentes: informação, expressão/mensagem e compreensão. A informação é uma seleção a partir de um repertório de possibilidades. A expressão/ mensagem é a forma e a razão da comunicação. Quando não há compreensão, não há comunicação. Há ainda outro aspecto considerado pelo autor, que é a aceitação ou rejeição da comunicação, manifestada em uma comunicação subsequente. Em um sistema social autopoiético, a comunicação só adquire sentido quando é relacionada com uma comunicação subsequente. Uma comunicação é produzida em uma rede de outras comunicações.

Para Luhmann (2006, p. 71), “a comunicação é a criação de uma realidade emergente, nomeadamente da sociedade, que, por seu lado, assenta na reprodução contínua da comunicação pela comunicação". Uma mensagem, iniciada por um indivíduo, é conduzida através de uma rede comunicativa e 
pode gerar uma multiplicidade de formas, conteúdos, compreensões, sentidos. A comunicação não transmite, e sim, multiplica possibilidades. Para haver comunicação, um esforço de comunicação precisa estar relacionado com um esforço seguinte, formando um contínuo. A sua reprodução é condicionada nessa rede e independe das mentes dos indivíduos.

No entanto, isso não quer dizer que a comunicação ocorra sem o envolvimento das consciências, que estão acopladas à comunicação da sociedade. Como observa Bachur (2009), a respeito da obra de Luhmann, trata-se de assegurar a irredutibilidade dessas duas dimensões (indivíduo e sociedade). Os sentidos são atualizados com a participação das consciências, que se ajustam aos suportes materiais dos sentidos institucionalizados na sociedade. A essa noção de comunicação aproximamos a abordagem de Verón (1996), que trata da não-linearidade entre produção e reconhecimento, e, consequentemente, da multiplicidade de efeitos dos discursos. Para o autor, os sentidos circulam no sistema e nunca produzem um efeito único, mas um campo de efeitos.

Esses sentidos circulam em uma rede discursiva ou rede de semiose, conforme Verón (1996), ou em uma rede recursiva ou uma rede de comunicação, de acordo com Luhmann (2011). Chegamos, assim, à compreensão da comunicação como um processo social de circulação, multiplicação e disputa de sentidos, que depende da interação entre sistemas (sociais e psicológicos). Esse processo é configurado nas improbabilidades e nos desvios entre produção e reconhecimento, formando uma rede complexa de sentidos, em que uma comunicação é condição para existência da outra.

Sob a perspectiva sistêmico-discursiva, podemos dizer, portanto, que a organização existe enquanto houver comunicação. Essa rede complexa de sentidos é continuamente (re)produzida no âmbito dos sistemas organizacionais e nas suas relações com o ambiente (formado por outros sistemas e por indivíduos). Além disso, como sistemas constituídos por comunicação, as organizações parecem ser constantemente observadas na/pela sociedade, o que pode deflagrar processos de construção e multiplicação de sentidos, que fogem ao seu controle, mas que contribuem, assim como os processos intencionais, para a configuração da organização nos âmbitos interno e externo. Assim, compreendemos que através da comunicação é construída e mantida a distinção entre sistema (organização) e ambiente, envolvendo tanto os processos formais, autorizados e planejados, quanto os processos informais, não-autorizados, não controláveis e não planejados. 


\section{Considerações}

Ao estudar a comunicação organizacional sob a perspectiva sistêmicodiscursiva, parece necessário explorar a rede discursiva ou a rede de semiose em que são construídos os sentidos, analisando as superfícies discursivas disponíveis, investigando as operações discursivas e as condições produtivas da circulação de sentidos na rede. Essa abordagem discursiva, no entanto, considerando os pressupostos sistêmicos, precisa reconhecer que os processos de construção de sentidos são autorreferenciados, ou seja, se configuram em formas circulares, autopoiéticas e operacionalmente fechadas. Os sistemas observam o entorno e constroem sentido tendo por referência um tecido autorreferenciado de comunicações.

Assim, sob essa perspectiva, somos levados a investigar, em discursos/ decisões, como as organizações se configuram através de seus processos comunicacionais, construindo e nutrindo a distinção fundamental que assegura sua condição sistêmica.

\section{Referências}

BACHUR, João Paulo. Distanciamento e crítica: limites e possibilidades da teoria de sistemas de Niklas Luhmann. 2009. 376 f. Tese (Doutorado em Ciência Política) - Faculdade de Filosofia, Letras e Ciências Humanas, Universidade de São Paulo, São Paulo, 2009.

BAKHTIN, Mikhail Mikhailovitch. Estética da criação verbal. São Paulo: Martins Fontes, 1992.

CURVELLO, João José A.; SCROFERNEKER, Cleusa Maria A. A comunicação e as organizações como sistemas complexos: uma análise a partir das perspectivas de Niklas Luhmann e Edgar Morin. E-compós: Revista da Associação Nacional dos Programas de Pós-Graduação em Comunicação, v.11, n.3, set/dez. 2008. Disponível em: <http://www.compos.org.br/seer/index.php/e-compos/article/ viewFile/307/300>. Acesso em: 14 mar. 2014.

CURVELLO, João José Azevedo. A perspectiva sistêmico-comunicacional das organizações e sua importância para os estudos da comunicação organizacional. In: KUNSCH, Margarida M. Krohling (Org.). Comunicação organizacional: histórico, fundamentos e processos. São Paulo: Saraiva, 2009. v.1, p. 91-106.

FOUCAULT, Michel. A ordem do discurso: aula inaugural no Collége de France, pronunciada em 2 de dezembro de 1970. São Paulo: Loyola, 1999.

HENRY, Paul. Os fundamentos teóricos da "Análise Automática do Discurso" de Michel Pêcheux. In: GADET, Françoise; HAK, Tony (Org.). Por uma análise automática 
do discurso: uma introdução a obra de Michel Pêcheux. Campinas: Ed. Unicamp, 1993.

LEITÃO, Sérgio Proença. Para uma nova teoria da decisão organizacional. RAP, Rio de Janeiro, v.31, n.2, p. 91-107, mar/abr. 1997.

LUHMANN, Niklas. Por que uma "teoria dos sistemas"? In: NEVES, Clarissa E. B.; SAMIOS, Eva M. B. (orgs.). Niklas Luhmann: a nova Teoria dos Sistemas. Porto Alegre: Ed. Universidade/UFRGS, Goethe-Institut/ICBA, 1997a.

Novos desenvolvimentos na teoria dos sistemas. In: NEVES, Clarissa E. B.; SAMIOS, Eva M. B. (Org.). Niklas Luhmann: a nova Teoria dos Sistemas. Porto Alegre: Ed. Universidade/UFRGS; Goethe-Institut/ICBA, 1997b.

O conceito de sociedade. In: NEVES, Clarissa E. B.; SAMIOS, Eva M. B. (Org.). Niklas Luhmann: a nova Teoria dos Sistemas. Porto Alegre: Ed. Universidade/ UFRGS, Goethe-Institut/ICBA, 1997c.

Complejidad y modernidade: de la unidad a la diferencia. Madrid:Trotta, 1998.

A realidade dos meios de comunicação de massa. São Paulo: Paulus, 2005a.

The paradox of decision making. In: SEIDL, David; BECKER, Kai H. (Org.). Niklas Luhmann and Organization Studies. Copenhagen: Copenhagen Business School Press, 2005b.

A improbabilidade da comunicação. Lisboa: Vega, 2006.

Introdução à teoria dos sistemas. Petrópolis: Vozes, 2011.

LYOTARD, Jean François. A condição pós-moderna. Rio de Janeiro: José Olympio, 2002.

MAINGUENEAU, Dominique. Análise de textos de comunicação. São Paulo: Cortez, 2008.

MARCONDES FILHO, Ciro. O escavador de silêncios. São Paulo: Paulus Editora, 2004.

Prefácio à edição brasileira: Niklas Luhmann, a comunicação vista por um novo olhar. In: LUHMANN, Niklas. A realidade dos meios de comunicação de massa. São Paulo: Paulus, 2005.

MATURANA, Humberto; VARELA, Francisco. A árvore do conhecimento: as bases biológicas do conhecimento humano. Campinas: Psy II, 1995.

PÊCHEUX, Michel. Semântica e discurso: uma crítica à afirmação do óbvio. Campinas: Ed. Unicamp, 2009.

RODRIGUES, Leo Peixoto; NEVES, Fabrício Monteiro. Niklas Luhmann: a sociedade 
como sistema. Porto Alegre: EDIPUCRS, 2012.

SOARES, Ana Thereza Nogueira. A comunicação organizacional sob o olhar teórico contribuições de Niklas Luhmann. In: CONGRESSO BRASILEIRO DE CIÊNCIAS DA COMUNICAÇÃO, 28, 2005, Rio de Janeiro. Anais do XXVIII Congresso Brasileiro de Ciências da Comunicação. Rio de Janeiro: INTERCOM - Sociedade Brasileira de Estudos Interdisciplinares da Comunicação, 2005, p. 1-12. Disponível em: $<$ http://www.intercom.org.br/papers/nacionais/2005/resumos/R0533-1.pdf>. Acesso em 08 set. 2014.

SIMON, Herbert A. Comportamento administrativo: estudo dos processos decisórios nas organizações administrativas. Rio de Janeiro: Fundação Getúlio Vargas, 1970.

VERÓN, Eliseo. A produção de sentido. São Paulo: Cultrix; Ed. da USP, 1980.

La semiosis social: fragmentos de una teoría de la discursividad. Barcelona: Gedisa, 1996.

Semiosis de lo ideológico y del poder: la mediatización. Buenos Aires: Oficina de Publicaciones del CBC, 1997 .

- Esquema para el análisis de la mediatización. Revista Diálogos de la Comunicación, n.48, 1997b.

Fragmentos de um tecido. São Leopoldo: Ed. Unisinos, 2004.

Recebido em: 28/05/2015

Aceito em: 9/09/2015

Endereço do autor:

Victor Márcio Laus Reis Gomes <victorlaus@gmail.com>

Universidade Católica de Brasília

Campus Avançado Asa Norte - SGAN 916 Módulo B Avenida W5

70790-160 - Brasília, DF - Brasil

Telefone: (61) 3448-7134

Campus Avançado Asa Sul - SHIGS 702 Conjunto 2 Bloco A

70330-710 - Brasília/DF - Brasil

Telefone: (61) 3226-8210 